\title{
LA ESCUELA Y LA REORGANIZACIÓN DEL ESPACIO Y DEL TIEMPO EN LA SOCIEDAD DE LA INFORMACIÓN
}

\section{Mercedes Ávila Francés*}

\section{El espacio de los lugares y el espacio de los flujos}

La sociedad globalizada de la era de la información supone una transformación radical del espacio y del tiempo. Espacio y tiempo son construcciones sociales, es decir, el significado o la concepción social del tiempo y del espacio varía de una cultura a otra. Y puesto que nuestras sociedades están sufriendo una transformación estructural, también están surgiendo nuevas formas y procesos espaciales (Castells, 1999: 444-445).

Según Castells (1999: 431), en la sociedad red el espacio organiza al tiempo, y la ciudad pasa de ser un lugar a ser un proceso. Esto supone la aparición de una nueva clase de espacio: el espacio de los flujos, donde la gente circula con un patrón cada vez más móvil. Coexisten, por tanto, dos tipos de espacios: los lugares y el espacio de los flujos.

Un lugar es un espacio físico con una historia, una cultura y sobre el que se asienta y en el que interactúan uno o más grupos sociales. La sociedad industrial se caracterizaba por la lógica de la especialización monofuncional: un lugar y un tiempo para cada cosa. En la sociedad de la información, un mismo lugar puede destinarse a distintas funciones en los diferentes momentos. Ese lugar puede servir entonces a distintos grupos sociales sin que a penas interactúen entre ellos, y puede tener un significado simbólico distinto para cada uno de ellos. Los espacios se vuelven multifuncionales.

La sociedad de la información está construida en torno a flujos: flujos de capital, flujos de información, flujos de tecnología, flujos de interacción organizativa, flujos de imágenes, sonidos y símbolos.

* Profesora de Sociología Universidad de Castilla-La Mancha. Miembro de la Asociación Castellano Manchega de Sociología. 
Los flujos no son sólo un elemento de la organización social: son los procesos que dominan nuestra vida económica, política y simbólica (Castells, 1999: 431).

En la sociedad red conviven estas dos formas de espacio: los lugares y los flujos: la gente sigue viviendo en lugares, pero la función y el poder se organizan en el espacio de los flujos. Esto puede llevar a una esquizofrenia estructural entre estas dos lógicas espaciales. "La tendencia dominante apunta hacia un horizonte de un espacio de flujos interconectado y ahistórico, que pretende imponer su lógica sobre lugares dispersos y segmentados, cada vez menos relacionados entre sí y cada vez menos capaces de compartir códigos culturales" (Castells, 1999: 461-462).

En la sociedad de la información, las funciones y los procesos dominantes cada vez se organizan más en torno a redes. Las redes constituyen la nueva morfología social. Pero la estructura espacial dominante no son las redes de lugares, sino las redes de flujos. Una red es un conjunto de nodos interconectados.

Jean Remy y Liliane Voyé (1985: 1090) hablan también de los espacios intermedios. Los espacios intermedios son aquellos que se desarrollan entre los espacios profesionales, regidos por reglas organizativas estrictas, y los espacios familiares, regidos por adhesiones afectivas que suponen intercambios que exceden cualquier cálculo. Los mismos autores destacan la importancia de estos espaciostiempos intermedios entre la familia y la escuela para la educación/formación de los niños y de los jóvenes. La práctica de deporte, la participación en talleres, el trabajo voluntario, etc., son un ejemplo de actividades intermedias.

Luego, ¿qué lógica debe seguir la escuela? ¿La de los lugares, la de los flujos, la de los espacios intermedios, o una combinación de las tres? ¿Cuál de las tres es, debe ser o será la dominante?

La escuela es un espacio en el que confluyen distintos grupos de personas guiados por intereses y lógicas distintas: trabajadores profesionales de la educación, otros trabajadores, niños, adolescentes, alumnos (que aunque son los niños y adolescentes anteriores suponen una categoría distinta), padres, madres (pues también existen diferencias entre éstas y los anteriores), políticos, monitores, voluntarios, etc. La escuela es por tanto un espacio de conflicto.

$\mathrm{Y}$ en este espacio de conflicto se dan las tres lógicas espaciales anteriores: para unos (profesores y alumnos sobre todo) es un lugar, para otros es un espacio de flujos (por ejemplo para las administraciones y los funcionarios y políticos de las mismas), y también puede ser un espacio intermedio (por ejemplo en las llamadas actividades extraescolares).

\section{La concepción del tiempo en la sociedad de la información}

La sociedad de la información también se caracteriza por la transformación del tiempo, conectado de forma inextricable con el surgimiento del espacio de los flujos. 
Las sociedades contemporáneas siguen estando dominadas por la noción del tiempo de reloj, un "descubrimiento mecánico/categórico" que para muchos marcó el inicio de una nueva era. Toda suerte de fenómenos, prácticas y lugares quedaron sometidos a la marcha del tiempo desarraigante, centralizador y universalizador".

Pero esta concepción del tiempo lineal, irreversible, medible y predecible es cada vez menos influyente en la sociedad red, pues estamos asistiendo a una relativización del tiempo según contextos sociales, o más aún, a la mezcla de tiempos. La tecnología permite escapar de los contextos cotidianos y apropiarse selectivamente de cualquier valor que cada contexto pueda ofrecer en un presente eterno. En la red el tiempo es atemporal.

El tiempo se gestiona como un recurso, no según el modo lineal y cronológico de la sociedad industrial de masas, sino como un factor diferencial en referencia a la temporalidad de otros procesos, grupos, actividades, etc.

A lo largo del siglo XX y hasta la década de 1980 aproximadamente se daban dos tendencias relacionadas en las economías industrializadas: el descenso del tiempo laboral por persona y por trabajador y la homogeneización y regulación del tiempo laboral como parte del contrato social que subyace en el Estado de bienestar. Sin embargo estas tendencias han sido modificadas recientemente hacia un modelo cada vez más complejo y variable. "Hoy el individuo está abrumado por las diversas temporalidades a las que tiene que hacer frente". La sociedad de la información supone un paso más hacia el desdibujamiento del ciclo vital y hacia la reconstrucción del ciclo vital en torno a categorías sociales.

En el espacio de los flujos el tiempo adopta dos formas diferentes: simultaneidad y atemporalidad; mientras que la disciplina temporal, el tiempo biológico y la secuenciación determinada por la sociedad caracterizan a los lugares.

\section{La reorganización del tiempo y la reorganización familiar}

El trabajo es, y lo será en un futuro previsible, el núcleo de la vida de la gente. De forma más específica, en las sociedades modernas, el tiempo laboral pagado estructura el tiempo social. En el tema del horario escolar interactúan dos lógicas diferentes: la de los trabajadores (docentes y no docentes) en el sistema educativo y la de los padres o familias. Los padres (o familias) se encuentran con dificultades para compaginar su rol de padre o madre y trabajador/a. El dilema que se plantea es: ¿deben adaptarse los padres o deben adaptarse los trabajadores del sistema educativo? El horario podría convertirse en una ventaja competitiva en un sistema descentralizado y desregularizado (en esta materia) en el que unos centros compiten con otros. El horario también podría convertirse en un factor de mayor calidad de vida para los padres. Pero el horario también es un factor muy importante de las condiciones (que las puede mejorar o empeorar) de trabajo de los trabajadores en el sistema educativo. 
El número de horas laborales y su distribución en el ciclo vital y en los ciclos anual, mensual, semanal y diario de las vidas de la gente son un rasgo condicionante de primer orden de su modo de vida. Su distribución diferente en los diversos grupos y categorías sociales acarrean modos de vida diferentes. El quid de la cuestión radica en que dichas diferencias no supongan desigualdad de oportunidades.

La flexibilidad de los horarios consistió en primer lugar en una estrategia de abaratamiento del trabajo recurriendo, para ello, a los contratos temporales y a tiempo parcial. Esto dio lugar a jornadas laborales y horarios atípicos en los trabajadores afectados, los cuales demandan a su vez flexibilidad de horarios en otras actividades (comercio, banca, escuela, etc.). Por otra parte, las jornadas laborales más cortas y los horarios atípicos, vinculados con el trabajo a tiempo parcial o temporal, se aplican sobre todo a las mujeres y a los jóvenes. Por tanto, la entrada masiva de mujeres en el mercado de trabajo se asocia, hasta cierto punto, con la diversificación de la posición y los horarios laborales. Y "la heterogeneidad de los horarios laborales en una sociedad con una participación similar de los géneros en la mano de obra, impone un reajuste espectacular de los acuerdos familiares" (Castells, 1999: 476-477).

La organización de actividades intermedias en la escuela introduce mayor flexibilidad en el horario escolar desde el punto de vista de los padres o familias pues aumenta el margen de variación a disposición de dichos padres/familias. Pero ¡cuidado!, lo que para unos es flexibilidad para otros supone, ya lo hemos dicho, jornadas laborales más cortas, horarios atípicos, trabajo a tiempo parcial o temporal, etc., es decir, trabajo precario.

Cada individuo participa en una multiplicidad de medios o ambientes que hace que el control ecológico ya no sea posible. Los individuos poseen un conocimiento parcial los unos de los otros. Incluso al nivel de la familia escapa al conjunto de sus miembros el dominio del tiempo, de los encuentros y de las actividades de cada uno de ellos.

La escuela es, nadie lo pone en duda, una institución básica, importantísima, pero existe un peligro de hipertrofia de dicha institución. El creciente proceso de personalización (hacia un individualismo cada vez mayor) supone la reducción del espacio y del tiempo familiar (me refiero al espacio y tiempo compartido por los miembros de una familia), lo que se pretende paliar con una ampliación del espacio y tiempo escolar. Pero esto no es un simple intercambio: familia y escuela son dos instituciones diferentes, por lo que la descarga de funciones de una a otra supondrá cambios importantes que es necesario analizar y anticipar para evitar efectos no deseados.

Agustín de la Herrán (2000), siguiendo a J. Cedrún, propone distinguir entre cuatro jornadas laborales distintas pero estrechamente relacionadas:

La jornada laboral de los profesores, compuesta por las horas de presencia en el centro, $y$ en las que no se incluye el tiempo dedicado a su formación permanente. 
- La jornada de los alumnos, en la que hay que distinguir a su vez:

o El tiempo lectivo, que es el tiempo que los alumnos pasan en el aula, bajo la dirección de un profesor.

o El tiempo escolar, que sería el tiempo total que los niños dedican a la escuela, y que incluiría el tiempo lectivo, los desplazamientos, las tareas en casa, etc. No se incluiría lo que se considera extraescolar o no directamente relacionado con el proyecto curricular de su etapa.

o El tiempo educativo, que sería el tiempo escolar más el tiempo de recreos, comedor, extraescolar, etc. (aunque sus actividades no guarden relación con el curriculum lectivo)

- La jornada laboral de padres y madres

- La jornada del centro escolar, que sería el tiempo potencialmente educativo de alumnos, profesores y padres/madres que el centro ofrece, y que no debiera vincularse rígidamente con ninguna de las jornadas anteriores. 


\section{BIBLIOGRAFÍA}

CASTELLS, M. (1999): La era de la información. Economía, sociedad y cultura. Vol. 1: la sociedad red, Alianza, Madrid.

DE LA HERRÁN, A. (2000): "El problema de la jornada escolar. Análisis, alternativas y posibles soluciones", Escuela española, núm. 3. 438.

GONZÁLEZ GRANDA, J. F. (2000): "Participación social en educación y tiempos escolares. Reflexiones en torno a la jornada escolar", Escuela española, núm. 3. 445.

MORÁN, C. (1999): "La lucha por las actividades extraescolares", El País, 1 de noviembre de 1999.

PÉREZ DE PABLOS, S. (1999): "El nuevo orden escolar. La polémica sobre la jornada abre el debate sobre la necesidad de reorganizar la escuela del futuro", El País, 1 de noviembre de 1999.

PÉREZ DE PABLOS, S. (2000): "La jornada escolar es cosa de mujeres", El País, 2 de marzo de 2000.

REMY, J. y VOYÉ, L. (1985): "La ciudad y la urbanización" en Lecturas de ecología humana, vol. III, Facultad de Ciencias Políticas y Sociología de la UCM, Madrid.

ZAPATER CORNEJO, M. (1999): "Calendario y horario escolar", Escuela española, núm. 3.432, 2 de diciembre. 